\author{
JURNAL EKONOMI \\ EFEKTIF
}

ISSN : $2622-8882$, E-ISSN : 2622-9935

Jurnal Ekonomi Efektif, Vol. 2, No. 4, Juli 2020

@) Prodi Manajemen Fakultas Ekonomi Universitas

Pamulang

\title{
PENGARUH KOMPETENSI TERHADAP PRODUKTIVITAS KARYAWAN PADA PT. ISS CABANG CILEGON
}

\author{
Udi Iswadi \\ STIE Al-Khairiyah, Cilegon, Banten, Indonesia \\ *iswadiu25@gmail.com
}

\begin{abstract}
ABSTRAK
Penelitian ini bertujuan untuk mengetahui pengaruh kompetensi terhadap produktivitas karyawan pada PT. ISS Cabang Cilegon. Metode yang digunakan adalah explanatory research dengan sampel sebanyak 97 responden. Teknik analisis menggunakan analisis statistik dengan pengujian regresi, korelasi, determinasi dan uji hipotesis. Hasil penelitian ini variabel kompetensi diperoleh nilai rata-rata skor sebesar 3,411 dengan kriteria baik. Variabel produktivitas karyawan diperoleh nilai rata-rata skor sebesar 3,841 dengan kriteria baik. Kompetensi berpengaruh positif dan signifikan terhadap produktivitas karyawan dengan nilai persamaan regresi $\mathrm{Y}=9,220+0,856 \mathrm{X}$, dan nilai koefisien korelasi 0,777 atau memiliki tingkat hubungan yang kuat dengan nilai determinasi $60,4 \%$. Uji hipotesis diperoleh signifikansi 0,000 $<0,05$.
\end{abstract}

\section{Kata Kunci: Kompetensi, Produktivitas Karyawan.}

\section{ABSTRACT}

This study aims to determine the effect of competence on employee productivity at PT. ISS Cilegon Branch. The method used is explanatory research with a sample of 97 respondents. The analysis technique uses statistical analysis with regression testing, correlation, determination and hypothesis testing. The results of this study of the competency variable obtained an average score of 3,411 with good criteria. Employee productivity variables obtained an average score of 3.841 with good criteria. Competence has a positive and significant effect on employee productivity with the regression equation value $Y=9.220+$ $0.856 X$, and the correlation coefficient value 0.777 or has a strong level of relationship with a determination value of $60.4 \%$. Hypothesis testing obtained a significance of $0.000<0.05$.

Keywords: Competence, Employee Productivity. 


\section{PENDAHULUAN}

\section{A. Latar Belakang Masalah}

Peranan produktivitas kerja karyawan sangat diharapkan pada suatu organisasi atau perusahaan, agar dapat mencapai target kerja serta untuk menjaga perusahaan agar tetap berjalan dengan baik. Beberapa faktor yang mempengaruhi produktivitas kerja seseorang, diantaranya adalah pengetahuan, keterampilan, kemampuan dan sikap. Kompetensi juga menunjukkan karakteristik pengetahuan dan keterampilan yang dimiliki atau dibutuhkan oleh setiap individu yang memampukan mereka untuk melakukan tugas dan tanggung jawab mereka secara efektif dan meningkatkan standar kualitas profesional dalam pekerjaan mereka. Kompetensi yang dimiliki oleh setiap karyawan sangat dibutuhkan agar dapat membantu pimpinan dalam menciptakan nilai dan memberikan kontribusi terhadap strategi dalam suatu perusahaan. Kompetensi setiap karyawan berbeda - beda, jadi dalam penempatan tugaspun haruslah sesuai dengan kemampuan karyawannya. Jika kompetensi tidak sesuai dengan penempatan tugasnya, maka produktivitas kerja yang diharapkan perusahaan tidak akan efektif dan efisien.

Menurut Keith Davis dalam (Nurarif \& Kusuma, 2013) yang menyatakan sifat umum yang mempengaruhi kesuksesan dalam mengelola dalam organisasi yaitu: intelegensia, kematangan sosial, motivasi diri, hubungan pribadi. Kepemimpinan transformasional merupakan kemampuan untuk mempengaruhi orang lain untuk mencapai tujuan dari suatu organisasi atau perusahaan. Sosok seorang pemimpin sangat dibutuhkan dalam rangka mendorong karyawannya agar mampu meningkatkan kualitas perusahaan terutama melalui motivasi dan peningkatan produktivitas karyawan.

Sumber daya manusia merupakan faktor penting yang menentukan kelangsungan hidup suatu perusahaan, maka karyawan menjadi aset yang lebih penting dibanding faktor produksi lainnya. Demikian juga yang terjadi di PT. ISS Cabang Cilegon. Sumber daya manusia merupakan faktor yang sangat penting mengingat PT. ISS Cabang Cilegon adalah perusahaan yang bergerak dalam bidang jasa penyediaan tenaga Security, Office Service, Messenger, dan Driver. Sebagai perusahaan yang berfokus pada pengembangan SDM, PT. ISS Cabang Cilegon menyelenggarakan kegiatan- kegiatan yang bergerak di bidang pengamanan, Office Service, Messenger, dan Driver. Ditemukan bahwa latar belakang pendidikan karyawan kantor pusat masih kurang memadai, bahkan di level pimpinan. Karyawan yang pendidikan S2 hanya satu orang, sehingga kurang mengutamakan pengetahuan dan kemampuan. Akibatnya penempatan pegawai tidak sesuai dengan kemampuan yang dimilikinya dan menyelesaikan tugas sering tidak sesuai dengan waktu yang sudah ditetapkan. Berdasarkan latar belakang di atas, maka penulis tertarik melakukan penelitian dengan judul "Pengaruh Kompetensi Terhadap Kompetensi Karyawan Pada PT. ISS Cabang Cilegon”

\section{B. Rumusan Masalah}

1. Bagaimana kompetensi pada PT. ISS Cabang Cilegon?.

2. Bagaimana produktivitas karyawan pada PT. ISS Cabang Cilegon?.

3. Adakah pengaruh antara kompetensi terhadap produktivitas karyawan pada PT. ISS Cabang Cilegon?.

\section{Tujuan Penelitian}

1. Untuk mengetahui kondisi kompetensi pada PT. ISS Cabang Cilegon.

2. Untuk mengetahui kondisi produktivitas karyawan pada PT. ISS Cabang Cilegon.

3. Untuk mengetahui pengaruh kompetensi terhadap produktivitas karyawan pada PT. ISS Cabang Cilegon. 


\section{TINJAUAN PUSTAKA}

\section{Kompetensi}

Menurut pendapat Wibowo (2019;324), mengemukakan "Kompetensi adalah suatu kemampuan untuk melaksanakan atau melakukan suatu pekerjaan atau tugas yang dilandasi atas keterampilan dan pengetahuan serta didukung oleh sikap kerja yang dituntut oleh pekerjaan tersebut". Dengan demikian, kompetensi menunjukkan keterampilan atau pengetahuan yang dicirikan oleh profesionalisme dalam suatu bidang tertentu sebagai sesuatu yang terpenting, sebagai unggulan bidang tersebut.

\section{Produktivitas Karyawan}

Menurut Sutrisno (2018:99) produkivitas adalah hubungan antara keluaran (barangbarang atau jasa) dengan masukan (tenaga kerja, bahan, uang). Produktivitas merupakan ukuran efisiensi produktif. Suatu perbandingan antara hasil keluaran dan masukan. Masukan sering dibatasi dengan tenaga kerja, sedangkan keluaran diukur dalam kesatuan fisik, bentuk, dan nilai. Menurut Sutrisno (2020:101) ada tiga aspek utama yang perlu ditinjau dalam menjamin produktivitas yang tinggi yaitu: a) Aspek kemampuan manajemen tenaga kerja, b) Aspek efesiensi tenaga kerja, c) Aspek kondisi lingkungan pekerjaan

\section{METODE PENELITIAN}

\section{Populasi}

Populasi dalam penelitian ini berjumlah 97 responden PT. ISS Cabang Cilegon

\section{Sampel}

Teknik pengambilan sampling dalam penelitian ini adalah sampel jenuh, dimana semua anggota populasi dijadikan sebagai sampel. Dengan demikian sampel dalam penelitian ini sampel yang digunakan berjumlah 97 responden.

\section{Jenis Penelitian}

Jenis penelitian yang dipakai adalah kuantitatif, dimana tujuannya adalah untuk mengetahui atau mencari keterhubungan antara variabel independen terhadap variabel dependennya

\section{Metode Analisis Data}

Dalam menganalisis data digunakan uji validitas, uji reliabilitas, analisis regresi linier sederhana, analisis koefisien korelasi, analisis koefisien determinasi dan pengujian hipotesis.

\section{HASIL PENELITIAN}

\section{Analisis Deskriptif}

Pada pengujian ini digunakan untuk mengetahui skor minimum dan maksimum skor tertinggi, ratting score dan standar deviasi dari masing-masing variabel. Adapun hasilnya sebagai berikut:

Tabel 1. Hasil Analisis Descriptive Statistics

\begin{tabular}{l|r|r|r|r|r}
\multicolumn{7}{c}{ Descriptive Statistics } & & \\
& N & Minimum & Maximum & Mean & Std. Deviation \\
\hline Kompetensi $(\mathrm{X})$ & 97 & 28 & 44 & 34.11 & 3.897 \\
\hline Produktivitas Karyawan $(\mathrm{Y})$ & 97 & 29 & 49 & 38.41 & 4.291 \\
\hline Valid N (listwise) & 97 & & & & \\
\hline
\end{tabular}

Kompetensi diperoleh varians minimum sebesar 28 dan varians maximum 44 dengan ratting score sebesar 3,411 dengan standar deviasi 3,897. Skor ini termasuk pada rentang 
sakala 3,40 - 4,19 dengan kriteria baik atau setuju.

Produktivitas karyawan diperoleh varians minimum sebesar 29 dan varians maximum 49 dengan ratting score sebesar 3,841 dengan standar deviasi 4,291. Skor ini termasuk pada rentang sakala 3,40-4,19 dengan kriteria baik atau setuju.

\section{Analisis Kuantitatif.}

Pada analisis ini dimaksudkan untuk mengetahui pengaruh variabel independen terhadap variabel dependen. Adapun hasil pengujian sebagai berikut:

\section{a. Analisis Regresi Linier Sederhana}

Uji regresi ini dimaksudkan untuk mengetahui perubahan variabel dependen jika variabel independen mengalami perubahan. Adapun hasil pengujiannya sebagai berikut:

Tabel 2. Hasil Pengujian Regresi Linier Sederhana

\begin{tabular}{|c|c|c|c|c|c|c|}
\hline \multirow[b]{3}{*}{ Model } & & \multicolumn{2}{|c|}{ Coefficients $^{a}$} & \multirow[b]{2}{*}{$\begin{array}{l}\text { Standardized } \\
\text { Coefficients }\end{array}$} & \multirow[b]{3}{*}{$\mathrm{t}$} & \multirow[b]{3}{*}{ Sig. } \\
\hline & & \multicolumn{2}{|c|}{$\begin{array}{l}\text { Unstandardized } \\
\text { Coefficients }\end{array}$} & & & \\
\hline & & B & Std. Error & Beta & & \\
\hline 1 & (Constant) & 9.220 & 2.441 & & 3.777 & .000 \\
\hline & Kompetensi (X) & .856 & .071 & .777 & 12.037 & .000 \\
\hline
\end{tabular}

a. Dependent Variable: Produktivitas Karyawan (Y)

Berdasarkan hasil pengujian pada tabel di atas, diperoleh persamaan regresi $\mathrm{Y}=$ $9,220+0,856 \mathrm{X}$. Dari persamaan tersebut dijelaskan sebagai berikut:

1) Konstanta sebesar 9,220 diartikan jika kompetensi tidak ada, maka telah terdapat nilai produktivitas karyawan sebesar 9,220 point.

2) Koefisien regresi kompetensi sebesar 0,856, angka ini positif artinya setiap ada peningkatan kompetensi sebesar 0,856 point maka produktivitas karyawan juga akan mengalami peningkatan sebesar 0,856 point.

\section{b. Analisis Koefisien Korelasi}

Analisis koefisien korelasi dimaksudkan untuk mengetahui tingkat kekuatan hubungan dari variabel independen terhadap variabel dependen. Adapun hasil pengujian sebagai berikut:

Tabel 3. Hasil Pengujian Koefisien Korelasi Kompetensi Terhadap Produktivitas Karyawan.

\begin{tabular}{|c|c|c|c|}
\hline \multicolumn{4}{|c|}{ Correlations $^{b}$} \\
\hline & & $\begin{array}{c}\text { Kompetensi } \\
(\mathrm{X})\end{array}$ & $\begin{array}{l}\text { Produktivitas } \\
\text { Karyawan }(\mathrm{Y})\end{array}$ \\
\hline \multirow[t]{2}{*}{ Kompetensi (X) } & Pearson Correlation & 1 & $.777^{* *}$ \\
\hline & Sig. (2-tailed) & & .000 \\
\hline \multirow[t]{2}{*}{ Produktivitas Karyawan (Y) } & Pearson Correlation & $.777^{\star \star}$ & 1 \\
\hline & Sig. (2-tailed) & .000 & \\
\hline
\end{tabular}

**. Correlation is significant at the 0.01 level (2-tailed).

b. Listwise $\mathrm{N}=97$

Berdasarkan hasil pengujian diperoleh nilai korelasi sebesar 0,777 artinya kompetensi memiliki hubungan yang kuat terhadap produktivitas karyawan.

\section{c. Analisis Koefisien Determinasi}

Analisis koefisien determinasi dimaksudkan untuk mengetahui besarnya persentase pengaruh dari variabel independen terhadap variabel dependen. Adapun hasil pengujian sebagai berikut:

Tabel 4. Hasil Pengujian Koefisien Determinasi Kompetensi Terhadap Produktivitas 
Karyawan.

\begin{tabular}{|c|c|c|c|c|}
\hline \multicolumn{5}{|c|}{ Model Summary } \\
\hline Model & $\mathrm{R}$ & R Square & $\begin{array}{l}\text { Adjusted R } \\
\text { Square }\end{array}$ & $\begin{array}{c}\text { Std. Error of the } \\
\text { Estimate }\end{array}$ \\
\hline 1 & $.777^{a}$ & .604 & .600 & 2.714 \\
\hline
\end{tabular}

a. Predictors: (Constant), Kompetensi (X)

Berdasarkan hasil pengujian diperoleh nilai determinasi sebesar 0,604 artinya kompetensi memiliki kontribusi pengaruh sebesar $60,4 \%$ terhadap produktivitas karyawan, sedangkan sisanya sebesar $39,6 \%$ dipengaruhi oleh faktor lain yang tidak dilakukan penelitian.

\section{d. Uji Hipotesis}

Pengujian hipotesis dengan uji $\mathrm{t}$ digunakan untuk mengetahui hipotesis mana yang diterima.

Rumusan hipotesis: Terdapat pengaruh yang signifikan kompetensi terhadap produktivitas karyawan.

Tabel 5. Hasil Uji Hipotesis Kompetensi Terhadap Produktivitas Karyawan.

\begin{tabular}{|c|c|c|c|c|c|c|}
\hline \multicolumn{7}{|c|}{ Coefficients $^{a}$} \\
\hline \multirow{2}{*}{\multicolumn{2}{|c|}{ Model }} & Unstandardiz & Coefficients & $\begin{array}{c}\text { Standardized } \\
\text { Coefficients }\end{array}$ & & \\
\hline & & B & Std. Error & Beta & $\mathrm{t}$ & Sig. \\
\hline & (Constant) & 9.220 & 2.441 & & 3.777 & .000 \\
\hline & Kompetensi (X) & .856 & .071 & .777 & 12.037 & .000 \\
\hline
\end{tabular}

a. Dependent Variable: Produktivitas Karyawan $(\mathrm{Y})$

Berdasarkan hasil pengujian pada tabel di atas, diperoleh nilai $\mathrm{t}$ hitung $>\mathrm{t}$ tabel atau $(12,037>1,985)$, dengan demikian hipotesis yang diajukan bahwa terdapat pengaruh yang signifikan atara kompetensi terhadap produktivitas karyawan diterima.

\section{Pembahasan Hasil Penelitian}

\section{Kondisi Jawaban Responden Variabel Kompetensi}

Berdasarkan jawaban responden, variabel kompetensi diperoleh ratting score sebesar 3,411 berada di rentang skala 3,40-4,19 dengan kriteria baik atau setuju.

\section{Kondisi Jawaban Responden Variabel Produktivitas Karyawan}

Berdasarkan jawaban responden, variabel produktivitas karyawan diperoleh ratting score sebesar 3,841 berada di rentang skala 3,40-4,19 dengan kriteria baik atau setuju.

\section{Pengaruh Kompetensi Terhadap Produktivitas Karyawan}

Kompetensi berpengaruh signifikan terhadap produktivitas karyawan dengan persamaan regresi $Y=9,220+0,856 X$, nilai korelasi sebesar 0,777 atau memiliki hubungan yang kuat dengan kontribusi pengaruh sebesar 60,4\%. Pengujian hipotesis diperoleh nilai t hitung $>\mathrm{t}$ tabel atau $(12,037>1,985)$. Dengan demikian hipotesis yang diajukan bahwa terdapat berpengaruh signifikan antara kompetensi terhadap produktivitas karyawan diterima.

\section{KESIMPULAN DAN SARAN}

1. Kesimpulan

a. Variabel kompetensi diperoleh ratting score sebesar 3,411 berada di rentang skala 3,40 $-4,19$ dengan kriteria baik atau setuju. 
b. Variabel produktivitas karyawan diperoleh ratting score sebesar 3,841 berada di rentang skala 3,40-4,19 dengan kriteria baik atau setuju.

c. Kompetensi berpengaruh signifikan terhadap produktivitas karyawan dengan persamaan regresi $\mathrm{Y}=9,220+0,856 \mathrm{X}$, nilai korelasi sebesar 0,777 atau kuat dan kontribusi pengaruh sebesar $60,4 \%$ sedangkan sisanya sebesar 39,6\% dipengaruhi faktor lain. Uji hipotesis diperoleh nilai $t$ hitung $>\mathrm{t}$ tabel atau $(12,037>1,985)$.

\section{Saran}

a. Perusahaan harus meningkatkan kegiatan pendidikan dan pelatihan secara periodik agar karyawan memiliki kemampuan kerja yang lebih baik lagi

b. Perusahaan harus membuat program pengembangan karir guna membantu karyawan dalam mencapai keinginan yang diharapkan terkait dengan bidang pekerjaannya.

c. Produktivitas karyawan perusahaan dapat ditingkatkan dengan memberdayakan karyawan dengan menegakkan peraturan yang baik dan pemberian pengembangan karir yang lebih inten lagi.

\section{DAFTAR PUSTAKA}

Ataunur, I., \& Ariyanto, E. (2015). Pengaruh Kompetensi dan Pelatihan terhadap Kinerja Karyawan PT Adaro Energy Tbk. Telaah Bisnis Volume 2 Nomor 6, 135-150.

Hermawati, R., \& Hidayat, R. R. (2019). Pengaruh Kepemimpinan Dan Kompetensi Terhadap Produktivitas Pegawai PPSU (Studi Kasus Di Penanganan Prasarana Dan Sarana Umum Pada Kelurahan Lebak Bulus Jakarta Selatan). JENIUS (Jurnal Ilmiah Manajemen Sumber Daya Manusia), 2(2), 189-211.

Ilham, D. (2014). Implementasi Nilai-Nilai Keagamaan pada Mata Pelajaran Umum dalam Upaya Peningkatan Akhlak Peserta Didik di MAN Malili Kabupaten Luwu Timur (Doctoral dissertation, STAIN/IAIN Palopo).

Ilham, D. (2019). Implementing Local Wisdom Values in Bride and Groom Course at KUA Bara SubDistrict, Palopo City. Jurnal Konsepsi, 8(1), 1-9.

Ilham, D. (2019). Menggagas Pendidikan Nilai dalam Sistem Pendidikan

Nasional. Didaktika: Jurnal Kependidikan, 8(3), 109-122.

Jasmani, J., \& Paeno, P. (2019). The Effect of Leadership and Competence on Lecturer Performance and Its Implications on Student Learning Motivation at Pamulang University. International Journal of Advances in Social and Economics, 1(4).

Jasmani, J., Maduningtias, L., \& Irmal, I. (2019). Pelatihan Dan Penguasaan Digital Marketing Dalam Meningkatkan Pendapatan Para Remaja Di Lingkungan Benda Timur IV. Jurnal Pengabdian Dharma Laksana, 2(1), 65-68.

Lilis-Suryani, N. (2017). Pengaruh Motivasi Dan Kompetensi Terhadap Kinerja Pegawai Pada Sekretariat Jenderal Dewan Perwakilan Daerah Republik Indonesia. JENIUS (Jurnal Ilmiah Manajemen Sumber Daya Manusia), 1(1).

Mangkunegara, A. P. (2009). Evaluasi Kinerja SDM. Bandung: PT Refika Aditama.

Moeheriono. (2012). Pengukuran Kinerja Berbasis Kompetensi. Jakarta: PT RajaGrafindo Persada.

Mulyadi. (2015). Manajemen Sumber Daya Manusia (MSDM). Bogor: In Media.

Noor, J. (2013). Metodologi Penelitian: Skripsi, Tesis, Disertasi, dan Karya Ilmiah. Jakarta: Kencana.

Oei, I. (2010). Riset Sumber Daya Manusia. Jakarta: PT Gramedia Pustaka Utama.

Rosanti, D. I., \& Budiyanto. (2014). Pengaruh Pendidikan, Kompetensi, Kompensasi terhadap 
Kinerja Karyawan PT Lati Prayogi. Jurnal Ilmu \& Riset Manajemen Vol. 3 No. 11, 1-16. Sedarmayanti. (2011). Manajemen Sumber Daya Manusia (Reformasi Birokrasi dan Manajemen Pegawai Negeri Sipil). Bandung: Refika Aditama.

Sugiyono. (2010). Metode Penelitian Bisnis (Pendekatan Kuantitatif, Kualitatif, dan R\&D). Bandung: Alfabeta.

Sunarsi, D., \& Kusjono, G. (2019). Pengaruh Lingkungan Kerja Non Fisik, Konflik Dan Turn Over Intention Terhadap Produktivitas Kerja Karyawan Pada CV. Usaha Mandiri Jakarta Selatan. Jurnal Ekonomi Efektif, 1(3).

Sutrisno, E. (2009). Manajemen Sumber Daya Manusia. Jakarta: Kencana.

Sutrisno, S., \& Sunarsi, D. (2019). The Effect of Work Motivation and Discipline on Employee Productivity at PT. Anugerah Agung in Jakarta. Jurnal Ad'ministrare, 6(2), 187-196.

Wibowo. (2009). Manajemen Kinerja. Jakarta: PT RajaGrafindo Persada.

Winanti, M. B. (2011). Pengaruh Kompetensi terhadap Kinerja Karyawan (Survei pada PT. Frisian Flag Indonesia Wiayah Jawa Barat). Majalah Ilmiah UNIKOM Vol. 7 No. 2 , 249-267. 